\title{
Role of nitric oxide and cGMP in the modulation of vascular contraction induced by angiotensin II and Bay K8644 during ischemia/reperfusion
}

\author{
KATARZYNA SZADUJKIS-SZADURSKA, GRZEGORZ GRZESK, \\ LESZEK SZADUJKIS-SZADURSKI, MARTA GAJDUS and GRZEGORZ MATUSIAK \\ Department of Pharmacology and Therapeutics, \\ Collegium Medicum Nicolaus Copernicus University, Bydgoszcz 85-094, Poland
}

Received April 2, 2012; Accepted November 1, 2012

DOI: $10.3892 /$ etm.2012.846

\begin{abstract}
Vascular smooth muscle tone changes under the influence of numerous contracting and relaxing factors. The purpose of the present study was to determine the modulating effect of ischemia and reperfusion (I/R) on contraction triggered by angiotensin II (ANG II) and Bay K8644 as well as to investigate the importance of nitric oxide (NO) and cGMP in these reactions. Experiments were performed on isolated and perfused Wistar rat tail arteries. The contraction triggered by ANG II and Bay K8644 with the use of intracellular (in calcium-free physiological salt solution; FPSS) and extracellular (in physiological salt solution; PSS) pools of calcium ions after I/R and in the presence of sodium nitroprusside (SNP), ${ }^{8} \mathrm{Br}-\mathrm{cGMP}$, an endothelial NO synthase (NOSe) inhibitor (L-NG-nitroarginine methyl ester; L-NAME) or ODQ [an inhibitor of soluble guanylyl cyclase (GC)] was evaluated. ANG II triggered contraction in FPSS and PSS, but Bay K8644 only in PSS. Ischemia reduced and reperfusion intensified the response of the artery to ANG II, but did not change the action of Bay K8644. SNP and ${ }^{8} \mathrm{Br}-\mathrm{cGMP}$ reduced the response of the vessels to ANG II and did not change the modulating effect of ischemia, but reduced the intensifying action of reperfusion on contraction caused by the presence of ANG II. SNP lowered the action of Bay K8644 in PSS. In PSS, L-NAME and ODQ intensified the action of ANG II, eliminating the reducing effect of ischemia on the contraction caused by ANG II, but did not influence the intensifying reaction caused by reperfusion. L-NAME and ODQ did not influence the action of Bay K8644. I/R modulated the contraction of arteries triggered
\end{abstract}

Correspondence to: Dr Katarzyna Szadujkis-Szadurska, Department of Pharmacology and Therapeutics, Collegium Medicum Nicolaus Copernicus University, 9 Skłodowskiej-Curie Street, Bydgoszcz 85-094, Poland

E-mail: kataszsz@gmail.com

Key words: angiotensin II, nitric oxide, Bay K8644, contraction, ischemia/reperfusion by ANG II, but did not influence the response to Bay K8644. The intra- and extracellular pools of calcium ions mediate the action of ANG II, but Bay K8644 stimulated contraction only with participation of calcium ions flowing into the cell. Control of the vascular smooth muscle tone associated with the action of NO and cGMP is subject to modulation under conditions of I/R.

\section{Introduction}

The contractibility of blood vessels depends on their normal structure and the availability of calcium ions; it changes under the influence of a number of contracting [e.g., angiotensin II (ANG II) and endothelin-1] and relaxing [e.g., nitric oxide (NO) and prostacyclin] factors, which control the activities of various pathways of intracellular and intercellular signaling (1-3). The endothelium lines the inside of the vessel and is not only an integral part of the vessel structure, but also actively participates in its normal functioning. Endothelial cells produce substances which regulate contraction-relaxation activity, but the action of the internal layer of the vessel is subject to the influence of various factors, acting via receptors $(1,4)$. Smooth muscle contraction, stimulated by a number of physiological factors, may take place with the participation of calcium ions released from the intracellular reserve, which flow from the extracellular space through the channels in the cellular membrane. However, an excessive increase in calcium ion concentration may promote cell death as a result of apoptosis, ischemia/reperfusion (I/R) and excitotoxicity (5-7). The smooth muscle is also important in the pathogenesis of vascular diseases, including sclerosis, arterial hypertension and restenosis $(8,9)$.

I/R and oxidative stress are pathological phenomena, which may change the reactivity of the vessels and modulate the effect of substances which control the vascular smooth muscle tone $(10,11)$. Tissue damage caused by hypoxia is mediated by mechanisms associated with oxygen (reactive oxygen species, ROS) and nitrogen (reactive nitrogen species, RNS) released in large amounts after reperfusion, which promote inflammatory processes, cell death and organ failure. Such phenomena are responsible for the failure of bypass graft surgery and organ 
transplantation surgery, as well as complications of myocardial, cerebral and renal hypoxia syndromes (12-15).

The purpose of the present study was to establish the modulating effect of I/R on contraction triggered by ANG II (an agonist of the metabotropic AT1 receptor) and Bay K8644 (an agonist of calcium channels located in the cellular membrane) as well as to investigate the role of the signaling pathway associated with NO and cGMP in these reactions.

\section{Material and methods}

Preparation of arteries. In the experiment, Guiding Principles for the Care and Use of Animals in the Field of Physiological Sciences as well as specific national laws were followed. The Ethical Committee for the Affairs of Experiments on Animals in Bydgoszcz approved the experiments undertaken (No. 1/2008-4). All reagents were purchased from Sigma-Aldrich (Poland, Poznań). Studies were performed on isolated and perfused Wistar rats' tail arteries. Animals, with body weights ranging from 250 to $350 \mathrm{~g}$, were anesthetized with urethane administered intraperitoneally at a dose of $120 \mathrm{mg} / \mathrm{kg}$ of body weight. In order to establish the effect of $\mathrm{I} / \mathrm{R}$ on the reactivity of the vascular smooth muscle triggered by ANG II (30 nM/l) and Bay K8644 (30 $\mu \mathrm{M} / \mathrm{l})$, a clamp was placed on the proximal segment of the prepared artery for 30 or $60 \mathrm{~min}$ and the artery was then removed. Then, a cannula was inserted into the proximal segment of the detached fragment of the rat's caudal artery measuring $2.5-3 \mathrm{~cm}$ in length, which was subsequently connected to the perfusion system and the equipment to allow constant measurement and recording of the perfusion pressure. The distal end of the prepared artery was loaded with a weight of $500 \mathrm{mg}$, and the preparation was placed in a vertical position in a thermostatic dish intended for isolated organs with a volume of $20 \mathrm{ml}$, oxygenated with saline at a temperature of $37^{\circ} \mathrm{C}$. The flow of the perfusion fluid was gradually increased until it reached $1 \mathrm{ml} / \mathrm{min}$. During the next stage, the contraction of the arteries was evaluated after 30, 60 and $120 \mathrm{~min}$ of reperfusion.

Assessment of role of calcium ion pools. In order to evaluate the involvement of intracellular and extracellular calcium ion pools in reactions triggered by the studied agonists under control conditions, following I/R and in the presence of sodium nitroprusside (SNP, $100 \mu \mathrm{M} / \mathrm{l}$ ) as a donor of NO, ${ }^{8} \mathrm{Br}-\mathrm{cGMP}$ (100 $\mu \mathrm{M} / 1)$, an endothelial NO synthase (NOSe) inhibitor (L-NG-nitroarginine methyl ester; L-NAME, $300 \mu \mathrm{M} / \mathrm{l}$ ) or ODQ [inhibitor of soluble guanylyl cyclase (GC), $100 \mu \mathrm{M} / 1$ ], the experiments were conducted using two types of Krebs fluid: i) Fluid without $\mathrm{Ca}^{2+}$-EGTA [Krebs (no calcium); calcium-free physiological salt solution (FPSS)], with the following composition: $\mathrm{NaCl}(71.8 \mathrm{mM} / \mathrm{l}), \mathrm{KCl}(4.7 \mathrm{mM} / \mathrm{l}), \mathrm{NaHCO}_{3}(28.4 \mathrm{mM} / \mathrm{l})$, $\mathrm{MgSO}_{4}(2.4 \mathrm{mM} / \mathrm{l}), \mathrm{KH}_{2} \mathrm{PO}_{4}(1.2 \mathrm{mM} / \mathrm{l})$ and glucose $(11.1 \mathrm{mM} / \mathrm{l})$ with the addition of EGTA $(30 \mu \mathrm{M} / \mathrm{l})$; ii) Fluid with $\mathrm{Ca}^{2+}$-EGTA [Krebs (normal); physiological salt solution (PSS)] with the the same composition as FPSS with $\mathrm{CaCl}_{2}(1.7 \mathrm{mM} / \mathrm{l})$, after emptying the intracellular pool of calcium ions.

Evidence for the vessel contraction in the conducted experiments included an increase in pressure of the perfusate in an experimental system, at a preset flow of the perfusion fluid $(\sim 1 \mathrm{ml} / \mathrm{min})$.

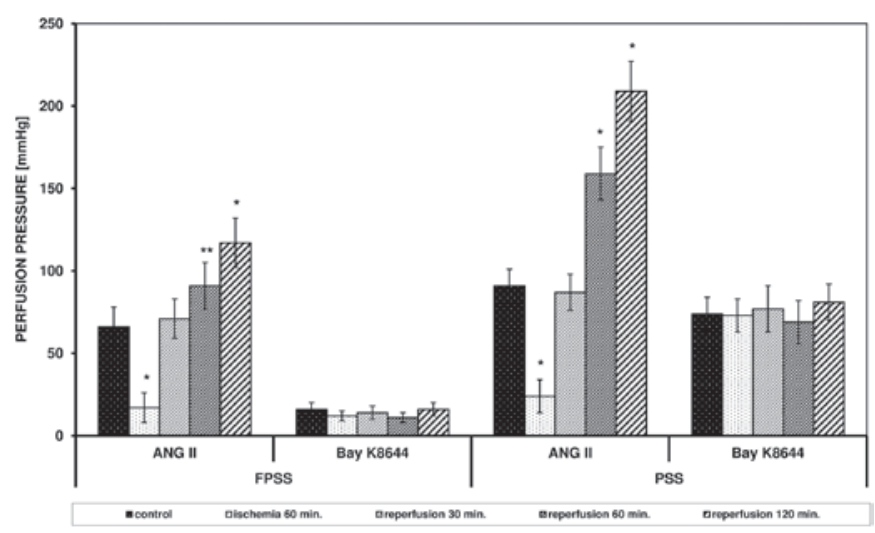

Figure 1. Effect of $60 \mathrm{~min}$ of ischemia and 30,60 and $120 \mathrm{~min}$ of reperfusion on response of the arteries to ANG II (30 nM/1) and Bay K8644 $(30 \mu \mathrm{M} / 1)$ in FPSS and PSS; (mean $\pm \mathrm{SE}, \mathrm{n}=12) ;{ }^{*} \mathrm{P}<0.0001$ vs. control; ${ }^{* *} 0.05>\mathrm{P}>0.0001$ vs. control. ANG II, angiotensin II; PSS, physiological salt solution; FPSS, calcium-free PSS.

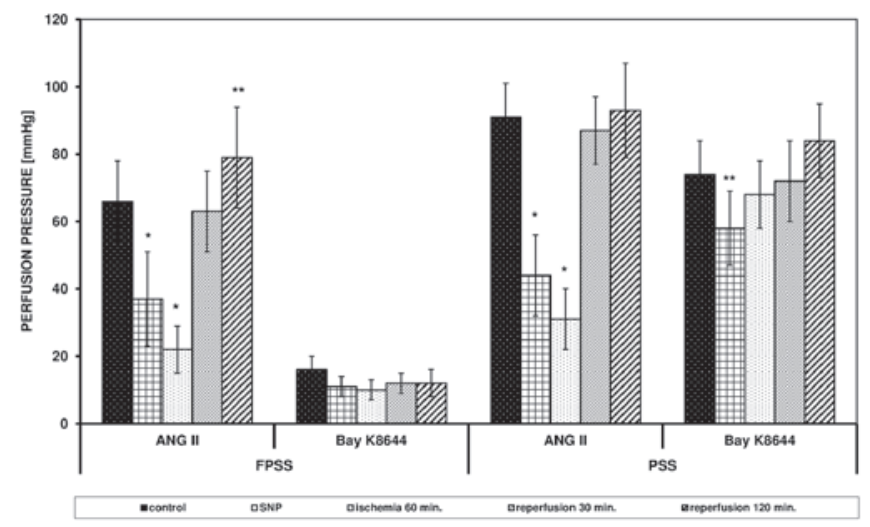

Figure 2. Effect of $60 \mathrm{~min}$ ischemia and 30 and $120 \mathrm{~min}$ of reperfusion on response of the arteries to ANG II (30 nM/1) and Bay K8644 (30 $\mu \mathrm{M} / 1)$ in the presence of SNP $(100 \mu \mathrm{M} / 1)$, in FPSS and PSS; (mean $\pm \mathrm{SE}, \mathrm{n}=12) ;{ }^{*} \mathrm{P}<0.0001$ vs. control; ${ }^{* *} 0.05>\mathrm{P}>0.0001$ vs. control. ANG II, angiotensin II; SNP, sodium nitroprusside; PSS, physiological salt solution; FPSS, calcium-free PSS.

Statistical analysis. Results are presented as average values and standard deviation. Statistical differences were evaluated using the Student's t-test. $\mathrm{P}<0.05$ was considered to indicate a statistically significant result. Calculations were conducted with Statistica 6.0PL software.

\section{Results}

Effects of ANG II and Bay K8644. ANG II triggered an increase in perfusion pressure in FPSS and PSS, but the values were higher in PSS (Fig. 1). After $60 \mathrm{~min}$ of ischemia, a reduced response of the arteries to ANG II was observed, but after 60 and $120 \mathrm{~min}$ of reperfusion, the maximum effects were significantly elevated in FPSS and PSS (in PSS after 60 and $120 \mathrm{~min} \mathrm{P}<0.0001$ vs. control; in FPSS after $60 \mathrm{~min}$ of reperfusion $0.05>\mathrm{P}>0.0001$ ). Bay K8644 triggered contraction only with the use of an extracellular pool of calcium ions, which, in contrast to the experiments with ANG II, was not modulated by I/R. The obtained values of reperfusion pressure triggered by ANG II and Bay K8644 following I/R in FPSS and PSS are presented in Fig. 1. 


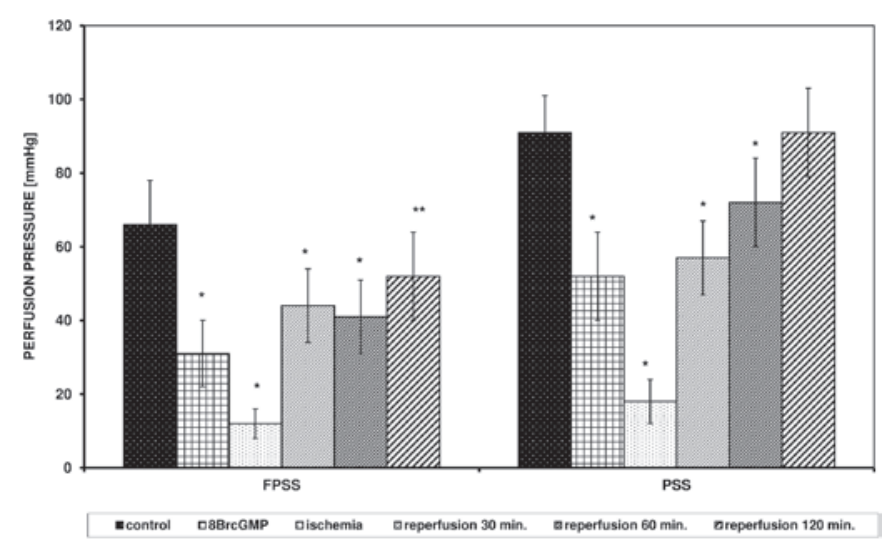

Figure 3. Effect of $60 \mathrm{~min}$ of ischemia and 30,60 and $120 \mathrm{~min}$ of reperfusion on response of the arteries to ANG II ( $30 \mathrm{nM} / \mathrm{l})$ in the presence of ${ }^{8} \mathrm{Br}$-cGMP $(100 \mu \mathrm{M} / 1)$, in FPSS and PSS; (mean $\pm \mathrm{SE}, \mathrm{n}=12)$; ${ }^{*} \mathrm{P}<0.0001$ vs. control; ${ }^{* *} 0.05>\mathrm{P}>0.0001$ vs. control. ANG II, angiotensin II; PSS, physiological salt solution; FPSS, calcium-free PSS.

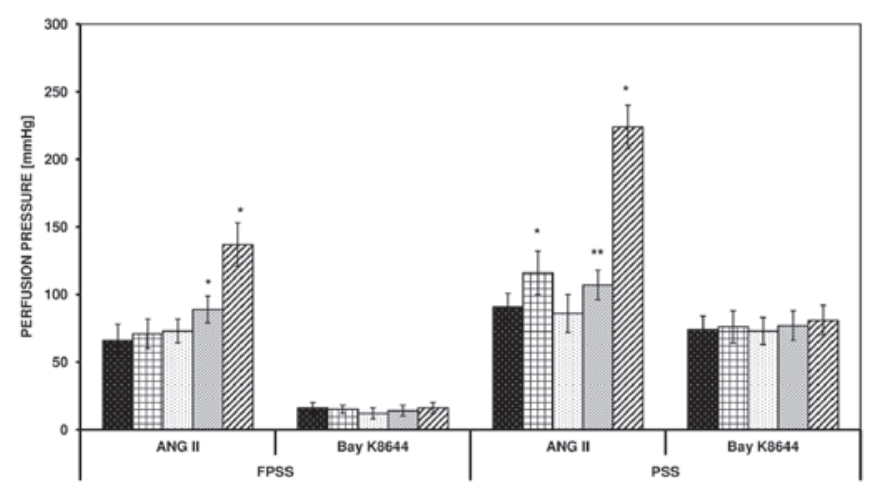

Figure 4. Effect of $60 \mathrm{~min}$ ischemia and 30 and $120 \mathrm{~min}$ of reperfusion on response of the arteries to ANG II (30 nM/l) and Bay K8644 (30 $\mu \mathrm{M} / \mathrm{l})$ in the presence of L-NAME $(300 \mu \mathrm{M} / 1)$, in FPSS and PSS; (mean $\pm \mathrm{SE}, \mathrm{n}=12)$; ${ }^{*} \mathrm{P}<0.0001$ vs. control; ${ }^{* *} 0.05>\mathrm{P}>0.0001$ vs. control. ANG II, angiontensin II; L-NAME, L-NG-nitroarginine methyl ester; PSS, physiological salt solution; FPSS, calcium-free PSS.

Effects of SNP and ${ }^{8} B r-c G M P$. The addition of SNP $(100 \mu \mathrm{M} / \mathrm{l})$ reduced the control response of the arteries to ANG II with involvement of intra- and extracellular pools of calcium ions and reduced the contraction triggered by Bay K8644 in PSS (Fig. 2).

SNP did not alter the effect of ischemia on contraction triggered by ANG II. In FPSS, the perfusion pressure was $22 \mathrm{mmHg}$ (vs. $17 \mathrm{mmHg}$ without SNP, P=0.24), and in PSS it was $31 \mathrm{mmHg}$ (vs. $24 \mathrm{mmHg}$ without $\mathrm{SNP}, \mathrm{P}=0.16$ ). The presence of SNP significantly reduced the intensifying effect of reperfusion on the response of the arteries triggered by ANG II. In FPSS, the pressure after 120 min of reperfusion was $79 \mathrm{mmHg}$ (vs. $117 \mathrm{mmHg}$ without $\mathrm{SNP}, \mathrm{P}=0.0002$ ), and in PSS it was $93 \mathrm{mmHg}$ (vs. $209 \mathrm{mmHg}$ without $\mathrm{SNP}, \mathrm{P}<0.0001$ ). SNP reduced the contraction triggered by Bay K8644 in PSS ( $\mathrm{P}=0.0088)$.

${ }^{8} \mathrm{Br}-\mathrm{cGMP}(100 \mu \mathrm{M} / \mathrm{l})$ changed the response of the arteries to ANG II after I/R in a manner similar to SNP (Fig. 3).

Effects of the inhibitors L-NAME and ODQ. L-NAME (an NOS inhibitor; $300 \mu \mathrm{M} / \mathrm{l}$ ) and ODQ (a cG inhibitor; $100 \mu \mathrm{M} / \mathrm{l}$ )

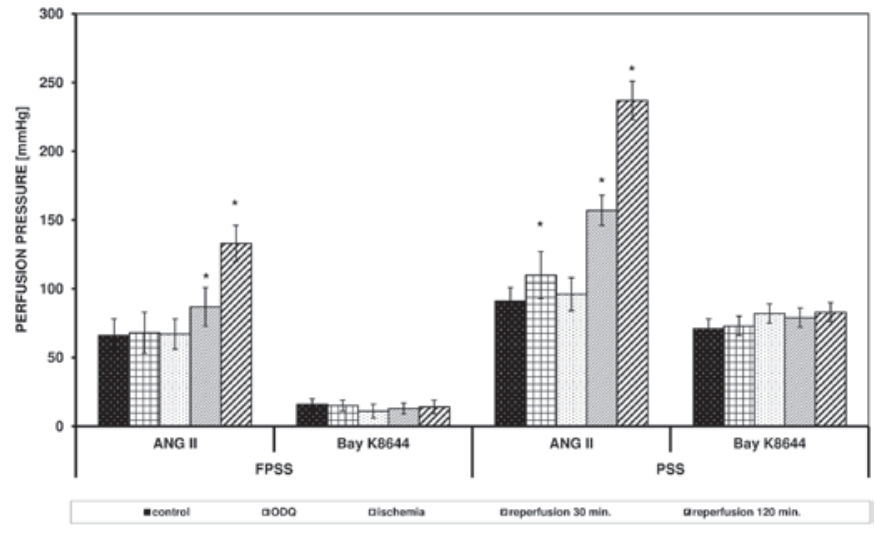

Figure 5. Effect of $60 \mathrm{~min}$ of ischemia and 30 and $120 \mathrm{~min}$ of reperfusion on response of the arteries to ANG II (30 nM/l) and Bay K8644 $(30 \mu \mathrm{M} / \mathrm{L})$ in presence of ODQ $(100 \mu \mathrm{M} / 1)$, in FPSS and PSS; (mean \pm SE, $\mathrm{n}=12)$; "P<0.0001 vs. control. ANG II, angiotensin II; ODQ, an inhibitor of soluble cG; PSS, physiological salt solution; FPSS, calcium-free PSS.

did not significantly influence the perfusion pressure triggered by ANG II with participation of an intracellular pool of $\mathrm{Ca}^{2+}$, but in PSS, an increased reaction was observed (91 vs. $116 \mathrm{mmHg}$ in the presence of L-NAME, $\mathrm{P}=0.0004 ; 91$ vs. $110 \mathrm{mmHg}$ in the presence of $\mathrm{ODQ}, \mathrm{P}=0.0022$; Figs. 4 and 5).

The two inhibitors eliminated the inhibitory effect of ischemia on the response of the arteries triggered by ANG II and increased the contraction resultant from reperfusion in FPSS and PSS (Figs. 4 and 5). After ischemia, in the presence of L-NAME, the perfusion pressure in PSS was $86 \mathrm{mmHg}$ (vs. $24 \mathrm{mmHg}$ without the inhibitor, $\mathrm{P}<0.0001)$, after $30 \mathrm{~min}$ of reperfusion the pressure reached $107 \mathrm{mmHg}$ (vs. $87 \mathrm{mmHg}$ without the inhibitor, $\mathrm{P}=0.0027)$. In PSS, following the addition of ODQ, the perfusion pressure after ischemia was $96 \mathrm{mmHg}$ (vs. $24 \mathrm{mmHg}$ without the inhibitor, $\mathrm{P}<0.0001$ ) and after $30 \mathrm{~min}$ of reperfusion it was $157 \mathrm{mmHg}$ (vs. $87 \mathrm{mmHg}$ without the inhibitor, $\mathrm{P}<0.0001$ ).

L-NAME and ODQ did not influence the action of Bay K8644.

\section{Discussion}

Surgical procedures, including bypass grafting and transplantations, are associated with temporary ischemia in organs and their reperfusion, which results in local contraction of the smooth muscles $(13,16)$. Elevated vascular muscle contractile tension following I/R triggers an excessive increase in calcium ion concentration as well as damage of the endothelial cells and the smooth muscles, which disturbs the balance between factors which stimulate the contraction and relaxation of the vessels, and may lead to total elimination of the blood flow $(11,17)$.

In the present study, the effect of I/R on contraction triggered by ANG II (an agonist of metabotropic angiotensin receptor AT1) and Bay K8644 (an agonist of calcium channels) was analyzed. In order to establish the significance of calcium ions (from intracellular reserves and the extracellular fluid), the experiments were conducted in fluid without calcium ions (for evaluation of the significance of the intracellular pool) and in 
standard Krebs fluid, after emptying the cellular reserves of calcium (for evaluation of the significance of the extracellular pool). Then, the effects of signaling pathways associated with $\mathrm{NO}$ and cGMP on the aforementioned reactions were evaluated.

The presented results reveal that in the case of contraction triggered by ANG II, the two pools of calcium ions mediate the response, but the response in PSS was more intense, and Bay K8644 led to an increase of the perfusion pressure only in the presence of calcium ions entering the cell from outside, since the action of Bay K8644 results from the direct activation of dihydropyridinic calcium channels located in the cellular membrane. Similar effects were also observed in studies which evaluated human mesenteric arteries $(18,19)$.

It is known that NO is a basic substance of endothelial origin, which triggers effects via cGMP $(20,21)$. Cyclic nucleotides, such as cAMP and cGMP, act contrary to calcium ions in smooth muscles. By lowering the level of $\left[\mathrm{Ca}^{2+}\right]_{\mathrm{i}}$ and the smooth muscle sensitivity to calcium ions, these nucleotides cause the vessel to relax (22-24). Besides the modulation of the smooth muscle, the signaling cascade $\mathrm{NO} \rightarrow \mathrm{cG} \rightarrow \mathrm{cGMP}$ inhibits artery proliferation and prevents aggregation and inflammatory effects, which indicates the potential suitability of this pathway, and the opportunity for the use of drugs administered in circulatory diseases (25-28).

Results of assays evaluating the response of the arteries to ANG II following I/R revealed that ischemia reduces and reperfusion intensifies the action of this peptide. The results of previous experiments have indicated that inhibiting the effect of ischemia on the contraction of arteries is associated with the presence of endothelium, NO synthesis and cGMP activation. The experiments which were conducted on rat tail arteries with removed endothelium revealed no reduction in response to ANG II following ischemia. However, intensification of the contraction following reperfusion was observed under these conditions (21). Studies on human mesenteric arteries revealed a modulating effect of NO, thromboxane A2 and guanylate cyclase on the reactivity of the vessels following I/R $(29,30)$. Finally, studies of the effects of catalase and aminotriazole on the contraction of the caudal artery in rats stimulated by ANG II after I/R revealed that an antioxidative system modulates the responses to ANG II, and reperfusion disturbs the balance between antioxidants and the production of ROS (31).

A series of experiments conducted on the influence of Bay K8644 revealed no effect of I/R on responses to direct activation of the dihydropyridinic calcium channels. Similarly, experiments using a depolarizing concentration of $\mathrm{KCl}$ revealed that ischemia does not influence the response of the arteries to $\mathrm{KCl}$ (27). It should be noted that in the present study SNP reduced the contraction triggered by Bay K8644 in PSS, but L-NAME and ODQ did not change the response mediated by the entry of calcium ions through channels located in the cellular membrane. Similar results have been achieved in experiments on human mesenteric arteries, and in addition, it has been revealed that an increasing concentration of acetylcholine reduces the contraction stimulated by Bay K8644, but does not change the reaction in the presence of L-NNA and ODQ (19).

In conclusion, I/R modulate the contraction of arteries triggered by ANG II, but do not influence the reactions induced by Bay K8644. Intra- and extracellular pools of calcium ions mediate the action of ANG II, but Bay K8644 stimulates contraction only with the participation of calcium ions entering the cell. Regulation of the vascular smooth muscle tone associated with the action of NO and cGMP is subject to modulation under conditions of I/R.

\section{References}

1. Lüscher TF and Barton M: Biology of the endothelium. Clin Cardiol 20 (Suppl 2): II-3-II-10, 1997.

2. Karaki H, Ozaki H, Hori M, et al: Calcium movements, distribution, and functions in smooth muscle. Pharmacol Rev 49: 157-230, 1997.

3. Touyz RM and Schiffrin EL: Signal transduction mechanisms mediating the physiological and pathophysiological actions of angiotensin II in vascular smooth muscle cells. Pharmacol Rev 52: 639-672, 2000.

4. Rubanyi GB: Endothelium-derived relaxing and contracting factors. J Cell Biochem 46: 27-36, 1991.

5. Choi DW: Calcium-mediated neurotoxicity: relationship to specific channel types and role in ischemic damage. Trends Neurosci 11: 465-469, 1988.

6. Fryer HJ, Knox RJ, Strittmatter SM and Kalb R: Excitotoxic death of a subset of embryonic rat motor neurons in vitro. J Neurochem 72: 500-513, 1999.

7. Schäfer M, Bahde D, Bosche B, Ladilov Y, Schäfer C, Piper HM and Noll T: Modulation of early $\left[\mathrm{Ca}^{2+}\right]_{\mathrm{i}}$ rise in metabolically inhibited endothelial cells by xestospongin C. Am J Physiol Heart Circ Physiol 280: H1002-H1010, 2001.

8. Bornfeldt KE: Intracellular signaling in arterial smooth muscle migration versus proliferation. Trends Cardiovasc Med 6: 143-151, 1996.

9. Katoh Y and Periasamy M: Growth and differentiation of smooth muscle cells during vascular development. Trends Cardiovasc Med 6: 100-106, 1996

10. Gutierrez J, Ballinger SW, Darley-Usmar VM and Landar A: Free radicals, mitochondria, and oxidized lipids: the emerging role in signal transduction in vascular cells. Circ Res 99: 924-932, 2006.

11. Hashimoto K, Pearson PJ, Schaff HV and Cartier R: Endothelial cell dysfunction after ischemia arrest and reperfusion: a possible mechanism of myocardial injury during reflow. J Thorac Cardiovasc Surg 102: 688-694, 1991.

12. Horner RL and Bradley TD: Update in sleep and control of ventilation. Am J Respir Crit Care Med 175: 426-431, 2007.

13. Szabo A and Heemann U: Ischemia reperfusion injury and chronic allograft rejection. Transplant Proc 30: 4281-4284, 1998.

14. Hangaishi M, Nakajima H, Taguchi J, et al: Lecithinized $\mathrm{Cu}$, Zn-superoxide dismutase limits the infarct size following ischemia-reperfusion injury in rat hearts in vivo. Biochem Biophys Res Commun 285: 1220-1225, 2001.

15. Zakynthinos S, Katsaounou P, Karatza MH, Roussos C and Vassilakopoulos T: Antioxidants increase the ventilatory response to hyperoxic hypercapnia. Am J Respir Crit Care Med 175: 62-68, 2007.

16. Fullerton DA, Mitchell MB, McIntyre RC Jr, Banerjee A, Campbell DN, Harken AH and Grover FL: Cold ischemia and reperfusion each produce pulmonary vasomotor dysfunction in the transplanted lung. J Thorac Cardiovasc Surg 106: 1213-1217, 1993.

17. Dignan RJ, Dyke CM, Abd-Elfattah AS, et al: Coronary artery endothelial cell and smooth muscle dysfunction after global myocardial ischemia. Ann Thorac Surg 53: 311-317, 1992.

18. Szadujkis-Szadurski R, Tafil-Klawe M, Szadujkis-Szadurska K, et al: Effect of acetylocholine on reactions induced by 2 contraction agents - angiotensin II and caffeine. Med Biol Sci 24: 53-58, 2010.

19. Szadujkis-Szadurski R, Tafil-Klawe M, Szadujkis-Szadurska K, et al: Modulation of the contractile effect of Bay K8644 on human vascular smooth muscle cells by acetylocholine and calcium ions. Med Biol Sci 24: 59-64, 2010.

20. Furchgott RF and Zawadzki JW: The obligatory role of endothelial cells in the relaxation of arterial smooth muscle by acetylcholine. Nature 288: 373-376, 1980.

21. Szadujkis-Szadurska K, Slupski M, Szadujkis-Szadurski R, Szadujkis-Szadurski L, Jasiñski M and Kolodziejska R: The role of the endothelium in the regulation of vascular smooth muscle cell contractions induced by angiotensin II after ischemia and reperfusion. Arch Pharm Res 33: 1019-1024, 2010. 
22. Zaccolo M and Movsesian MA: cAMP and cGMP signaling cross-talk: Role of phosphodiesterases and implications for cardiac pathophysiology. Circ Res 100: 1569-1578, 2007.

23. Bender AT and Beavo JA: Cyclic nucleotide phosphodiesterases: molecular regulation to clinical use. Pharmacol Rev 58: 488-520, 2006.

24. Münzel T, Daiber A, Ullrich V and Mülsch A: Vascular consequences of endothelial nitric oxide synthase uncoupling for the activity and expression of the soluble guanylyl cyclase and the cGMP-dependent protein kinase. Arterioscler Thromb Vasc Biol 25: 1551-1557, 2005.

25. Yetik-Anacak G, Xia T, Dimitropoulou C, Venema RC and Catravas JD: Effects of hsp90 binding inhibitors on sGC-mediated vascular relaxation. Am J Physiol Heart Circ Physiol 291: H260-H268, 2006.

26. Oberwittler H, Hirschfeld-Warneken A, Wesch R, et al: Significant pharmacokinetic and pharmacodynamic interaction of warfarin with the NO-independent sGC activator HMR1766. J Clin Pharmacol 47: 70-77, 2007.
27. Yan C, Kim D, Aizawa T and Berk BC: Functional interplay between angiotensin II and nitric oxide: cyclic GMP as a key mediator. Arterioscler Thromb Vasc Biol 23: 26-36, 2003.

28. Martin E, Sharina I, Kots A and Murad F: A constitutively activated mutant of human soluble guanylyl cyclase (sGC): Implication for the mechanism of sGC activation. Proc Natl Acad Sci USA 100: 9208-9213, 2003.

29. Slupski M, Szadujkis-Szadurska K, Szadujkis-Szadurski R, et al: Nitric oxide and thromboxane A2 modulate pulmonary pressure after ischemia and intestinal reperfusion. Transplant Proc 38: 334-337, 2006.

30. Slupski M, Szadujkis-Szadurski L, Grześk G, et al: Guanylate cyclase activators influence reactivity of human mesenteric superior arteries retrieved and preserved in the same conditions as transplanted kidneys. Transplant Proc 39: 1350-1353, 2007.

31. Szadujkis-Szadurska K, Slupski M, Szadujkis-Szadurski R, et al: Modulation of the reaction of vascular smooth muscle cells to angiotensin II induced by catalase and aminotriasol during ischemia-reperfusion. Transplant Proc 42: 1614-1617, 2010. 